BMJ Open

Diabetes

Research

\& Care

\title{
Prevalence, control, and treatment of diabetes, hypertension, and high cholesterol in the Amish
}

Shisi He, Kathleen A Ryan, Elizabeth A Streeten, Patrick F McArdle, Melanie Daue, Donna Trubiano, Yvonne Rohrer, Patrick Donnelly, Maryann Drolet, Sylvia Newcomer, Susan Shaub, Nancy Weitzel, Alan R Shuldiner, Toni I Pollin, Braxton D Mitchell

To cite: He S, Ryan KA, Streeten EA, et al. Prevalence, control, and treatment of diabetes, hypertension, and high cholesterol in the Amish. BMJ Open Diab Res Care 2020;8:e000912. doi:10.1136/ bmjdrc-2019-000912

Received 9 0ctober 2019 Revised 12 July 2020 Accepted 18 July 2020
Check for updates

\section{(C) Author(s) (or their} employer(s)) 2020. Re-use permitted under CC BY-NC. No commercial re-use. See rights and permissions. Published by BMJ.

Department of Medicine, Division of Endocrinology, Diabetes and Nutrition, University of Maryland School of Medicine, Baltimore, Maryland, USA

Correspondence to Dr Braxton D Mitchell; bmitchel@som.umaryland.edu

\section{ABSTRACT}

Background The burden of diabetes and cardiovascular risk is not uniform across the USA, with much of this disparity tracking differences in socioeconomic status, cultural practices and lifestyle. To further evaluate disparities in these disorders, we assessed the prevalence of diabetes, hypertension, and hypercholesterolemia in an Old Order Amish community that is characterized by distinctive sociocultural practices that include a very cohesive social structure and limited use of modern technologies and medications. We compared prevalence of these conditions with that of the overall US population. Method We performed a community-wide survey in 5377 Amish individuals aged 18 years and older from the Lancaster County, Pennsylvania, Amish settlement that included a basic physical examination and fasting blood draw during the period 2010-2018. We then compared the prevalence of diabetes, hypertension, and high cholesterol, defined using standard criteria, between the Amish and the European Caucasian subsample of the 2013-2014 US National Health and Nutrition Examination Survey (NHANES).

Results Prevalence rates for diabetes, hypertension and hypercholesterolemia were $3.3 \%, 12.7 \%$, and $26.2 \%$ in the Amish compared with $13.2 \%, 37.8 \%$ and $35.7 \%$ in NHANES $(p<0.001$ for all). Among individuals with these disorders, Amish were less likely to be aware that they were affected, and among those aware, were less likely to be treated with a medication for their disorder.

Conclusion There is substantially lower prevalence of diabetes, hypertension and hypercholesterolemia in the Amish compared with non-Amish Caucasians in the USA. Possible factors contributing to this disparity include higher physical activity levels in the Amish or other protective sociocultural factors, a greater understanding of which could inform risk reduction interventions for these chronic diseases.

\section{INTRODUCTION}

Heart disease is the leading cause of death in the USA, and by the year 2035, over 130 million adults in the US population are projected to have some form of cardiovascular disease (CVD) with total costs projected to reach $\$ 1.1$ trillion. ${ }^{1}$ Among the major risk factors

\section{Significance of this study}

What is already known about this subject?

- Differences in diabetes and cardiovascular risk exist across many populations, and these differences are often used to speculate about the relative importance of lifestyle and other factors in diabetes and heart disease risk.

What are the new findings?

- Compared with the overall non-Hispanic white population in the USA, the Amish community from Lancaster, Pennsylvania, experiences significantly lower prevalence rates of diabetes, hypertension, and high cholesterol.

- These associations persist even after adjustment for body mass index.

- Amish are less lilkely to be aware of having these conditions and, among those aware, are less likely to be treated with a medication.

How might these results change the focus of research or clinical practice?

- Possible factors contributing to this disparity include higher physical activity levels in the Amish or other protective sociocultural factors. A greater understanding of these may inform risk reduction interventions for these chronic diseases.

for CVD are hypertension, hypercholesterolemia, and diabetes. In 2005, it was estimated that hypertension alone was responsible for $45 \%$ of all cardiovascular deaths. ${ }^{2}$ Deaths due to CVD in the USA increased steadily in the 20th century until about 1980, after which point CVD-attributable deaths have slowly

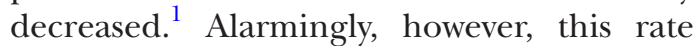
has leveled off beginning in about 2010. Of particular concern is that the prevalence of the major CVD risk factors continues to be high. In fact, the prevalence of hypertension among US adults increased between 1988 and 1999 to a rate of $28.5 \%$, although this rate has not changed through 2012. ${ }^{34}$ Diabetes 
prevalence among US adults has increased steadily from 1988 to 2012, at which point the population prevalence was estimated at $14.3 \% .^{5}$ In contrast, the proportion of individuals with high total and low-density lipoprotein (LDL) cholesterol levels have decreased over the past 30 years, although this decrease has been accompanied by an increase in use of cholesterol-lowering medications. ${ }^{6-8}$

The burden of CVD and its risk factors is not uniform across the country, and comparisons across subpopulations can be informative in highlighting health disparities and providing insights into disease risk. One such subpopulation is the Old Order Amish (OOA), a rural population isolate with distinctive sociocultural practices that includes a very cohesive social structure and limited use of modern technologies. The oldest Amish settlement in the USA is in Lancaster County, Pennsylvania, which is currently home to 38000 Amish. Through community surveys of CVD and its risk factors, we have estimated the prevalence of the major CVD risk factors. In this paper, we report the prevalence and control of diabetes, hypertension, and high cholesterol in the Amish, contrasting these estimates with those obtained from the US National Health and Nutrition Examination Survey (NHANES).

\section{RESEARCH DESIGN AND METHODS}

The Lancaster County Amish

The OOA of Lancaster County, Pennsylvania, are a population isolate. The OOA first immigrated to America from Central Europe, primarily present-day Switzerland, in the early 1700s. The Lancaster area community remains the largest of the Amish settlements in the USA, with an estimated size of $\sim 38000,{ }^{9}$ virtually all descendants of the original founders. ${ }^{10}$ The present report is based on subjects participating in the Amish Wellness Study, a community survey carried out to assess cardiovascular and metabolic health, disseminate this information to study participants, and evaluate associations of genetic and other risk factors with common diseases and related traits. These analyses are limited to 5377 adult participants of the Amish Wellness Study enrolled between its initiation in January 2010 and February 2018.

\section{Recruitment}

The Amish community in Lancaster County is divided into church districts, each consisting of up to 50 households. Enrollment into the wellness study was structured around church districts, and data for this report are compiled from subjects in the initial 101 (of a total of 122) church districts. We targeted these initial church districts because of their proximity to our Amish Research Clinic in Lancaster. For each selected church district, our recruitment teams (consisting of a research nurse and Amish liaison) first visited each household and invited the heads of the household to participate. If the head of household agreed, then he or she in turn invited all ageeligible ( $\geq 18$ years) persons in their household to participate. At this visit, the team obtained informed consent for a clinical exam, administered medical history questionnaires, and scheduled subjects for an appointment.

The study examinations were conducted in the Amish Research Clinic or the Amish Wellness mobile, a refurbished recreation vehicle that includes walk-in space for participant interviews, anthropometry and blood pressure measurements, a blood drawing station, and a centrifuge for blood processing. Blood pressure was measured in triplicate on a sphygmomanometer, and blood pressure was defined as the average of all three readings. Fasting bloods were drawn and sent to Quest Diagnostics (Horsham, Pennsylvania) for measurement of lipids and glucose. Glycosylated hemoglobin (HbAlc) was not added to the Amish protocol until November 2013 and so diabetes was assessed in only 3302 (61.4\%) of the Amish subjects with HbAlc, fasting glucose, and medication data.

\section{Disease definitions}

Disease definitions (diabetes, hypertension, and hypercholesterolemia) were harmonized for these analyses to match those used in the NHANES 2013-2014 cycle. Subjects had diabetes if they were currently taking blood glucose-lowering medications (and had previously been told by a doctor that they had diabetes) or had a fasting blood glucose $\geq 126 \mathrm{mg} / \mathrm{dL}$ or an HbAlc $\geq 6.5 \%$. All other subjects not meeting these criteria were considered not to have diabetes.

Subjects were considered to have hypertension if they were currently taking blood pressure-lowering medications (and had previously been told by a doctor that they had high blood pressure) or had a systolic blood pressure $(\mathrm{SBP}) \geq 140 \mathrm{~mm} \mathrm{Hg}$ or a diastolic blood pressure (DBP) $\geq 90 \mathrm{~mm} \mathrm{Hg}$. Blood pressures were measured in $99.9 \%(5,370 / 5,377)$ of Amish subjects and in $93.7 \%$ $(2408 / 2571)$ of NHANES subjects. Blood pressures were calculated by taking the mean of up to three blood pressure readings. Of the subjects with blood pressure data, all Amish and $99.7 \%$ of NHANES had more than two blood pressure readings. Subjects reporting that they were currently taking cholesterol-lowering medications or had total cholesterol levels $\geq 240 \mathrm{mg} / \mathrm{dL}$ or LDL cholesterol levels $\geq 160 \mathrm{mg} / \mathrm{dL}$ were considered to have high total cholesterol or high LDL cholesterol, respectively. Forty-nine Amish participants reported a negative history of hypertension, but a review of their current medications indicated that they were currently taking a blood pressure-lowering medication. These subjects were therefore considered to have hypertension. Similarly, 12 Amish subjects reported a negative history of high cholesterol, but a review of their current medications indicated that they were currently taking a cholesterol-lowering medication. These subjects were considered to have high cholesterol. We were unable to review the current medications of NHANES subjects, and therefore all NHANES subjects reporting a negative history of hypertension or high cholesterol were considered to be unaffected 
providing that they met the blood pressure or cholesterol criteria.

We considered persons with diagnosed diabetes, hypertension, or high cholesterol to be 'aware' of their disease if they reported that they had previously been told by a doctor that they had diabetes/hypertension or that they had high levels of fat or cholesterol or triglyceride in their blood. We considered persons with diagnosed disease to be treated if they were 'aware' of their disease and also reported that they were currently taking a medication for their disease.

\section{European Caucasians}

We compared diabetes, hypertension, and hypercholesterolemia prevalence in the Amish with that in non-Amish participants from the 2013-2014 cycle of NHANES. NHANES data are downloaded from https://www.cdc. gov/nchs/nhanes. We used only European Caucasians from NHANES $(n=2571)$ to match the European ancestry of the Amish.

\section{Statistical analysis}

We compared the frequencies of diabetes, hypertension, and hypercholesterolemia between Amish and NHANES stratified by age group using Poisson regression to calculate the prevalence rate ratio (PRR) using the SAS V.9.4 software. For total cholesterol, we compared Amish and NHANES both in all subjects and after excluding 12.5\% of Amish who are carriers of the known $A P O B$ R3527Q mutation that is common in the Amish and is a known cause of familial hypercholesterolemia. ${ }^{11}$ Among subjects meeting diagnostic criteria for diabetes, hypertension, or hypercholesterolemia, we compared by $\chi^{2}$ test the proportion of subjects responding that they had previously been told by a doctor of their disease (ie, were 'aware' of their disease), and we compared the proportions of Amish and NHANES subjects currently taking medications for their disease (ie, 'treated') among those 'aware' of their disease. We did not use NHANES sampling weights in these analyses because we used Caucasians from NHANES only and stratified all analyses by age and sex.

\section{RESULTS}

This report is based on 5377 subjects recruited into the Amish Wellness Study between 2010 and 2018. The mean household response rate across church districts was $65.6 \%$; that is, $\sim 2 / 3$ of households in each church district had at least one participating family member (range: $20 \%-93 \%)$. The mean age of study participants was 43.7 years (range 18-93), and mean body mass index was $26.7 \mathrm{~kg} / \mathrm{m}^{2}$ (range: $15.1-68.5$ ). The study participants were $42.6 \%$ male $(n=2291)$. The overall prevalence rates for diabetes, hypertension, and hypercholesterolemia were $3.3 \%, 12.7 \%$, and $26.2 \%$, respectively (table 1 ). For comparison, mean age in the NHANES population was 50.0 years $(18-80), 47.9 \%$ of subjects were male $(n=1231)$, and mean BMI was $29.0(14.2-70.1) \mathrm{kg} / \mathrm{m}^{2}$. The overall prevalence rates in NHANES for diabetes, hypertension, and hypercholesterolemia were $13.2 \%, 37.8 \%$, and $35.7 \%$, respectively (table 1 ). In general, the sex differences in the prevalence of diabetes, hypertension, and high cholesterol observed in the Amish mirrored those seen in NHANES. After adjustment for age and sex, the prevalence rates for diabetes, hypertension, and hypercholesterolemia were significantly higher in NHANES compared with Amish, and these differences persisted with further adjustment for body mass index (table 1).

The prevalence of diabetes in the Amish increased from $0.6 \%$ (95\% CI $0.3 \%$ to $1.0 \%$ ) to $4.6 \%$ (95\% CI $3.4 \%$ to $6.2 \%$ ) to $11.7 \%$ (95\% CI $8.9 \%$ to $15.0 \%$ ) across the three age groups (18-44, 45-64, and 65+ years) (figure 1 and table 2). The corresponding prevalence rates in NHANES were $4.4 \%, 15.1 \%$, and $24.2 \%$. The age-adjusted and sexadjusted prevalence of diabetes was $3.3 \%$ and $13.1 \%$ in the Amish and NHANES, respectively (PRR: 0.34 (95\% CI 0.27 to 0.42 ), $\mathrm{p}<0.001$ ). Among subjects with diabetes, 11 Amish (representing 10.2\% of all Amish subjects with diabetes) and 14 NHANES (representing $4.3 \%$ of all NHANES subjects with diabetes) were currently taking insulin and reported an age of diabetes onset before the age of 25 years. Thus, a larger proportion of Amish subjects with diabetes may potentially have type 1 dabetes mellitus (T1DM) compared with NHANES subjects with diabetes. We have previously published that Amish individuals with age of diabetes diagnosis $\leq 35$ years, but not those with age of diabetes diagnosis $>35$ years, are significantly more likely to be glutamic acid decarboxylase (GAD) antibody positive than Amish individuals without diabetes. ${ }^{12}$ However, the overall prevalence of diabetes is much lower in Amish than NHANES, and in terms of population prevalence, Amish were less likely to have potential T1DM $(11 / 3302$, or $0.3 \%)$ compared with NHANES (14/2444, or $0.6 \%)$.

Because $\mathrm{HbAlc}$ was not measured in the first 4 years of the wellness study, we assessed the comparability of the 3302 wellness participants with HbA1c values (from November 2013 to January 2018) with the 2067 wellness participants without HbAlc values (January 2010 October 2013). The proportion of subjects who were currently using glucose-lowering medications was virtually identical between the two groups $(1.8 \%$ vs $1.8 \%$, $\mathrm{p}=0.83$ ). Similarly, the frequency of diabetes based on medication use and fasting glucose criteria only was also similar between the two groups $(2.5 \%$ vs $2.7 \%, \mathrm{p}=0.72)$.

The prevalence of hypertension in the Amish increased from $1.8 \%$ (95\% CI $1.4 \%$ to $2.3 \%$ ) to $17.6 \%$ (95\% CI $15.7 \%$ to $19.6 \%$ ) to $46.4 \%$ (95\% CI $42.8 \%$ to $50.0 \%$ ) in individuals across the three age groups (figure 2 and table 2). The corresponding prevalence rates in NHANES were $11.5 \%, 43.3 \%$, and $71.8 \%$. The age-sex-adjusted prevalence of hypertension was $12.7 \%$ and $37.8 \%$ in the Amish and NHANES, respectively (PRR: 0.46 (95\% CI 0.42 to 0.51$), \mathrm{p}<0.0001$ ).

The prevalence of high total and LDL cholesterol was higher in the Amish than in NHANES in the 18-44 years age group (18.2\% vs $13.4 \%$ for total cholesterol and 


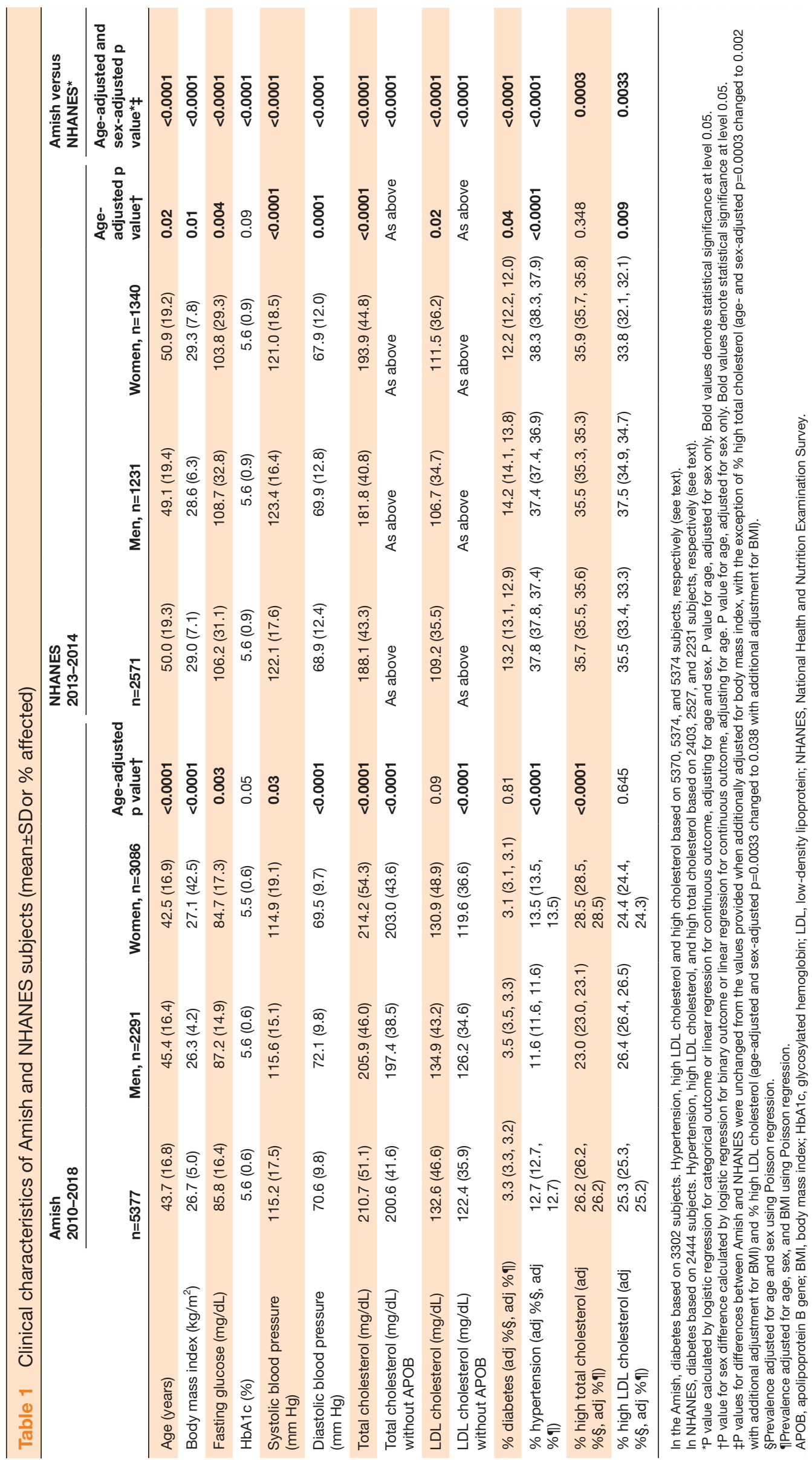


- Amish a NHANES

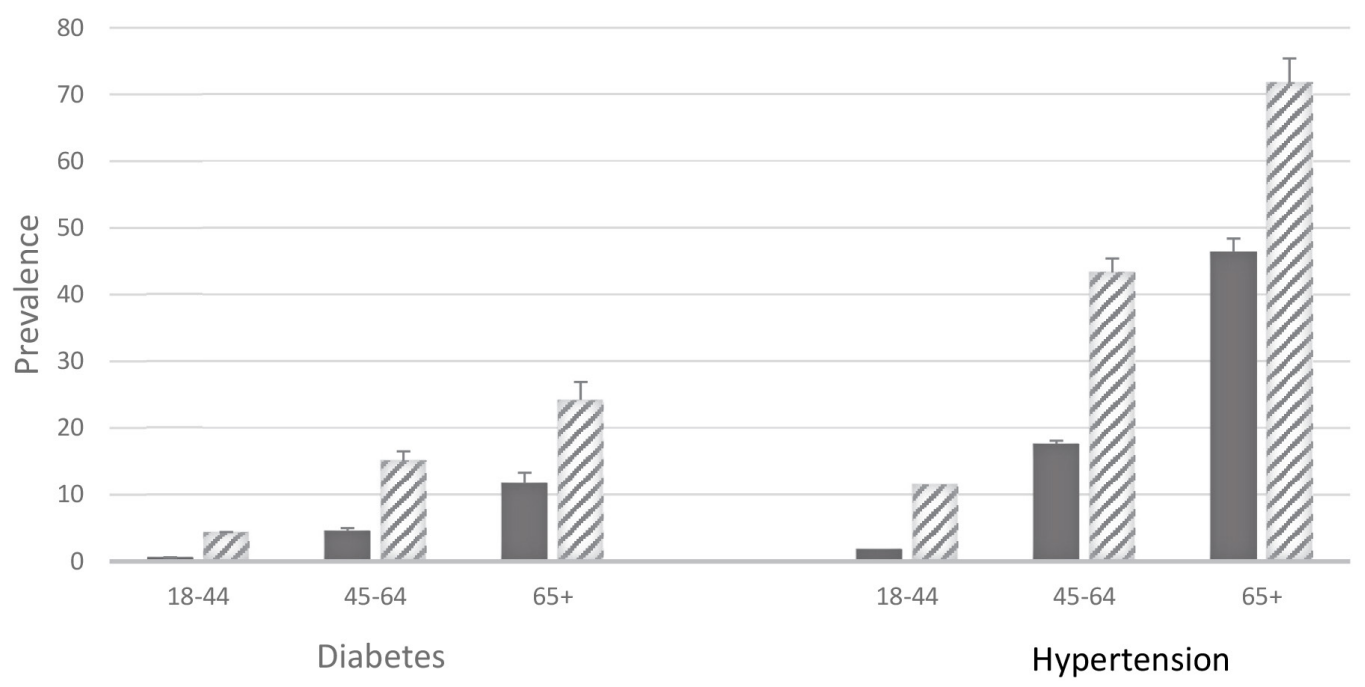

Figure 1 Prevalence of diabetes and hypertension in Amish versus NHANES by age group. See text for diagnostic criteria. NHANES, National Health and Nutrition Examination Survey.

$18.4 \%$ vs $11.3 \%$ for LDL cholesterol), although lower in the Amish in the two older age categories $(33.7 \%$ vs $40.8 \%$ and $31.6 \%$ vs $37.8 \%$ for total and LDL cholesterol, respectively, at ages $45-64$ years, and $43.2 \%$ vs $63.1 \%$ and $40.3 \%$ vs $62.1 \%$ for total and LDL cholesterol, respectively, at ages $65+$ years) (figure 2 and table 2). Overall, the age-adjusted and sex-adjusted prevalence of high total cholesterol was $26.2 \%$ and $35.7 \%$ in the Amish and NHANES, respectively (PRR: 0.87 (95\% CI 0.80 to 0.94 ), $\mathrm{p}<0.0001)$ and the age-adjusted and sex-adjusted prevalence of high LDL was $25.3 \%$ and $35.5 \%$ in the Amish and NHANES, respectively (PRR: 0.87 (95\% CI 0.79 to $0.95), p=0.0016)$. After excluding Amish subjects with the $A P O B \mathrm{R} 3527 \mathrm{Q}$ mutation, the prevalence of high total and LDL cholesterol was lower in the Amish at all ages and the prevalence of high total cholesterol was $37 \%$ lower in the Amish than in NHANES (PRR: 0.63 (95\% CI 0.57 to $0.70), \mathrm{p}<0.0001)$ and the prevalence of high LDL cholesterol was $39 \%$ lower (PRR: 0.60 (95\% CI 0.54 to 0.67 ), $\mathrm{p}<0.0001)$.

Since the Amish are significantly less likely to take physician-prescribed medications than NHANES and thus less likely to be diagnosed on the basis of medication use alone, we considered the possibility that the lower frequency of hypertension and hypercholesterolemia observed in the Amish might be an artifact of the diagnostic criteria for these conditions being less sensitive in the Amish. If this were true, then one might expect to see that among those without a diagnosis of hypertension (or high cholesterol), mean levels of blood pressure (or cholesterol) would be higher in Amish than in NHANES, although below the diagnosis criteria for disease diagnosis. To evaluate this possibility, we therefore compared mean blood pressures and cholesterol levels between Amish and NHANES among individuals not diagnosed with hypertension or high cholesterol. Among individuals without hypertension, mean SBP was $4.5 \mathrm{~mm} \mathrm{Hg}$ lower in Amish than in NHANES $(110.6 \pm 11.3$ vs $115.0 \pm 10.6 \mathrm{~mm}$ $\mathrm{Hg}$, age-adjusted and sex-adjusted $\mathrm{p}<0.0001)$, while mean DBP was slightly higher in Amish (69.0 \pm 8.4 vs $68.6 \pm 9.6$, $\mathrm{p}=0.04$ ). Similarly, among individuals without diabetes, mean fasting glucose was $13.4 \mathrm{mg} / \mathrm{dL}$ lower in Amish than in NHANES $(83.9 \pm 8.8$ vs $97.3 \pm 10.0 \mathrm{mg} / \mathrm{dL}$, age-adjusted and sex-adjusted $\mathrm{p}<0.0001)$, although mean $\mathrm{HbAlc}$ was slightly higher in Amish (5.5 \pm 0.3 vs $5.4 \% \pm 0.4 \%$, $\mathrm{p}<0.0001)$. In contrast, among individuals without a diagnosis of high total cholesterol, mean total cholesterol was $9.4 \mathrm{mg} / \mathrm{dL}$ higher in Amish than in NHANES $(189.2 \pm 28.7$ vs $179.8 \pm 31.4 \mathrm{mg} / \mathrm{dL}, \mathrm{p}<0.0001)$. Similarly, Amish had mean LDL cholesterols that were $9.2 \mathrm{mg} / \mathrm{dL}$ higher $(113.6 \pm 25.9$ vs $104.4 \pm 27.4 \mathrm{mg} / \mathrm{dL}, \mathrm{p}<0.0001)$.

\section{Control and treatment}

Among individuals meeting diagnostic criteria for diabetes, hypertension, or hypercholesterolemia, Amish are less likely to be aware of their disease compared with NHANES (figure 3). For example, $51.3 \%$ of Amish with hypertension are aware of their disease compared with $87.6 \%$ of NHANES $(\mathrm{p}<0.0001)$ and $38.3 \%$ of Amish with high total blood cholesterol are aware of their disease compared with $79.4 \%$ of NHANES $(\mathrm{p}<0.0001)$. Differential awareness of diabetes was much smaller, with $63.6 \%$ of Amish with diabetes aware of their disease compared with $71.7 \%$ of NHANES $(p=0.17$ ).

Among those 'aware' of their disease, Amish were also less likely to report that they were currently taking medications to treat their disease compared with NHANES. For example, $72.1 \%$ of Amish aware of their diabetes reported taking glucose-lowering medications compared with $84.7 \%$ of NHANES $(\mathrm{p}=0.30)$. Similarly, $62.3 \%$ of 
Amish aware of their hypertension reported taking blood pressure-lowering medications compared with $96.4 \%$ of NHANES ( $p<0.0001)$, and $30.6 \%$ of Amish aware of their hypercholesterolemia reported taking cholesterollowering medications compared with $90.2 \%$ of NHANES $(\mathrm{p}<0.0001)$.

Among subjects diagnosed with diabetes the proportion of Amish and NHANES achieving treatment targets for $\mathrm{HbAlc}(<7 \%)$ were comparable $(49.1 \%$ vs $55.2 \%$; age-adjusted and sex-adjusted PRR $=0.89 ; 95 \%$ CI 0.66 to $1.21 ; \mathrm{p}=0.56$ ). In contrast, only $12.2 \%$ of Amish with hypertension achieved treatment targets for blood pressure control (target of SBP $<130 \mathrm{~mm} \mathrm{Hg}$ or DBP $<80 \mathrm{~mm} \mathrm{Hg}$ ) compared with $39.5 \%$ for NHANES (ageadjusted and sex-adjusted PRR $=0.31 ; 95 \%$ CI 0.24 to $0.39 ; \mathrm{p}<0.0001$ ) and only $1.2 \%$ of Amish with high total cholesterol achieved the $<150 \mathrm{mg} / \mathrm{dL}$ treatment target for cholesterol compared with $16.9 \%$ for NHANES (ageadjusted and sex-adjusted PRR=0.15; 95\% CI 0.09 to 0.23 ; $\mathrm{p}<0.0001)$. The proportion of subjects with high LDL achieving the LDL treatment target of $<130 \mathrm{mg} / \mathrm{dL}$ was $8.8 \%$ in Amish compared with $64.0 \%$ in NHANES (ageadjusted and sex-adjusted PRR $=0.20 ; 95 \%$ CI 0.16 to 0.25 ; $\mathrm{p}<0.0001)$.

\section{DISCUSSION}

We have shown that Amish have a lower prevalence of diabetes, hypertension, and hypercholesterolemia compared with non-Amish Caucasians. The magnitudes of the differences in disease rates between the two populations are striking, that is, a $66 \%$ lower prevalence of diabetes, $54 \%$ lower prevalence of hypertension, and a $13 \%$ lower prevalence of high total cholesterol. There is no evidence that the decreased prevalence of hypertension in the Amish is an artifact of NHANES with subthreshold levels of blood pressure being more likely than Amish to be treated with blood pressure lowering medications since SBP among non-hypertensive individuals is on average higher, not lower, in NHANES. However, among individuals not meeting diagnostic criteria for high cholesterol, cholesterol levels are on average slightly higher (by $\sim 9 \mathrm{mg} / \mathrm{dL}$ ) in Amish than in NHANES. We cannot therefore rule out the possibility that some of the difference in hypercholesterolemia prevalence rates might be due to non-Amish being more likely than Amish to have cholesterol levels in the high normal range and therefore more likely to be prescribed cholesterol-lowering medications.

Despite the lower frequency of diabetes, hypertension, and hypercholesterolemia in the Amish, these disorders still constitute significant public health problems in this community because of their associations with adverse events. This is especially true since Amish individuals with these disorders are less likely than NHANES to be aware that they are affected and less likely to be treated. Amish diagnosed with hypertension and high cholesterol are also less likely than NHANES to meet target treatment 


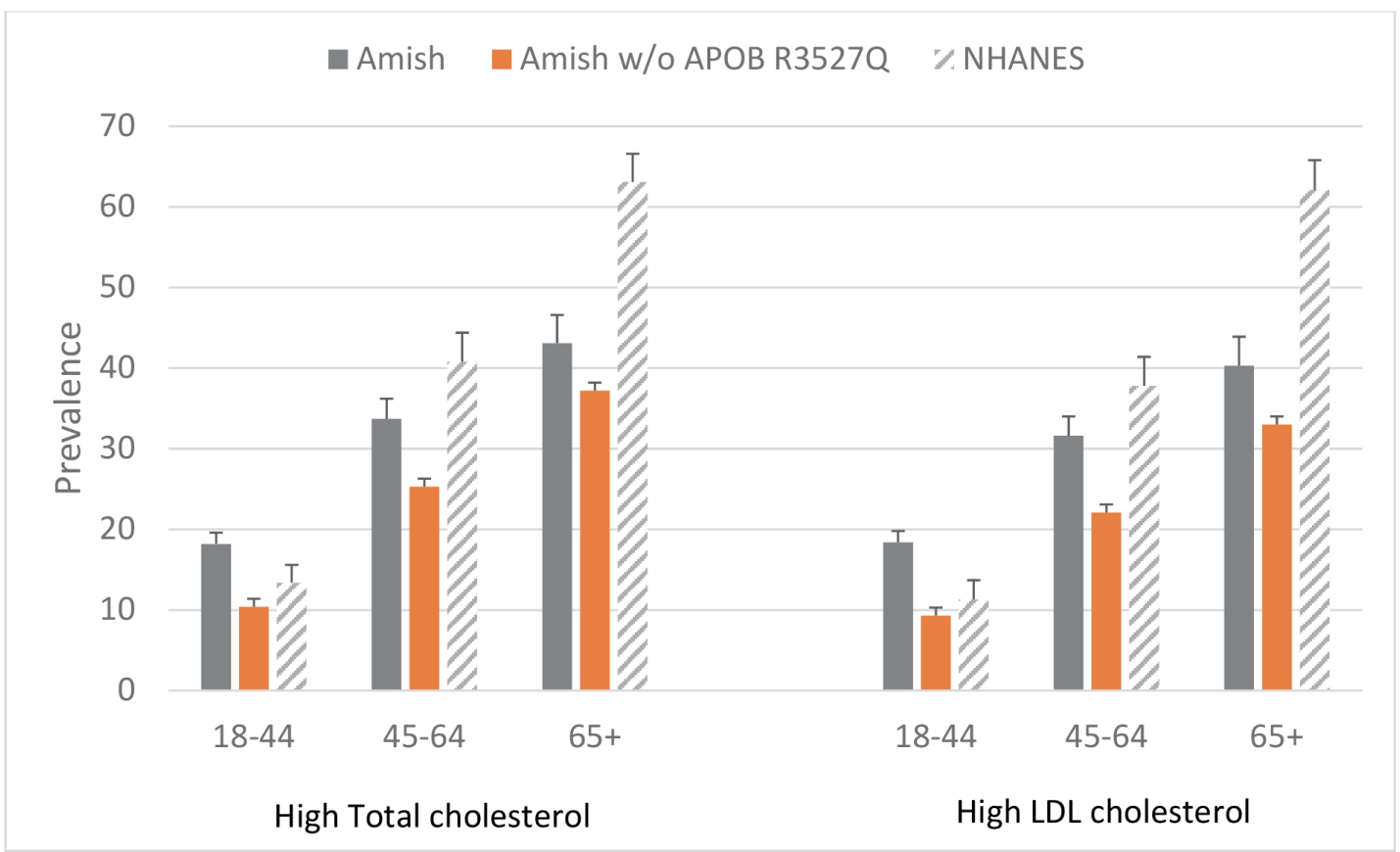

Figure 2 Prevalence of high total cholesterol and high LDL cholesterol in Amish and NHANES by age group. See text for diagnostic criteria. APOB, apolipoprotein B gene; LDL, low-density lipoprotein; NHANES, National Health and Nutrition Examination Survey.

guidelines. These results might be expected given that Amish do not participate in government-sponsored medical insurance programs and are less likely to receive medical care compared with non-Amish Caucasians in the USA.

The lower prevalence of hypercholesterolemia in the Amish occurs despite the fact that $12 \%$ of Amish carry at least one copy of a familial hypercholesterolemiaassociated allele at the $A P O B$ locus that is associated with a $\sim 70 \mathrm{mg} / \mathrm{dL}$ increase in LDL cholesterol levels. Moreover, if individuals with the $A P O B \mathrm{R} 3527 \mathrm{Q}$ mutation, a highly drifted variant associated with familial hypercholesterolemia carried by $12 \%$ of the Amish population, are excluded, Amish have a 37\% lower prevalence of high total cholesterol. The Amish are also enriched for at least one other known genetic variant (near the pseudogene, APOOP1) that is also associated with high LDL cholesterol levels, with $15 \%$ of Amish carrying at least one copy of this variant and each copy associated with $\sim 15 \mathrm{mg} / \mathrm{dL}$ increase in LDL cholesterol. ${ }^{13}$ Because of these mutations, the prevalence of high cholesterol is actually higher in younger Amish than in younger nonAmish, but as other (non-genetic) causes of high cholesterol become more prominent with age, the prevalence of high cholesterol becomes higher in the non-Amish beginning in middle age.

It seems likely that there are distinctive features about the Amish community or Amish lifestyle that contribute to their relative protection against diabetes, hypertension, and high cholesterol. Two features in particular stand

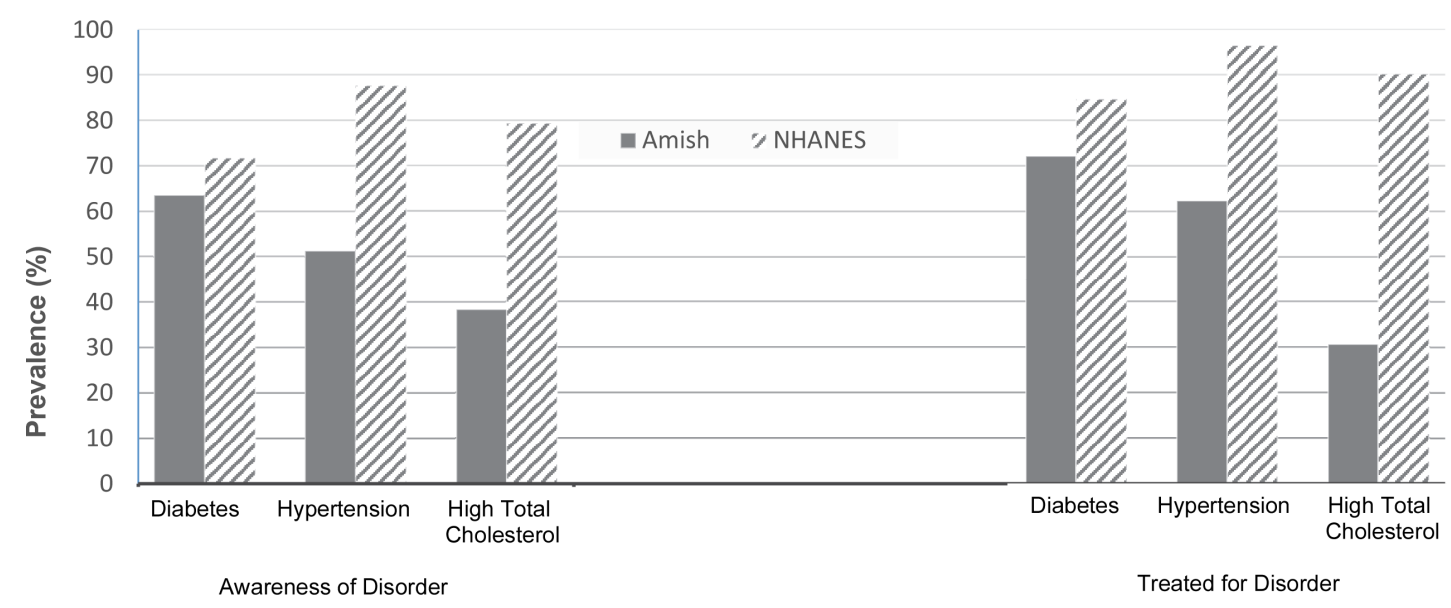

Figure 3 Proportion of individuals with diabetes, hypertension, and high total cholesterol disease who are aware of their diagnosis, and among those aware, the proportion who are treated. NHANES, National Health and Nutrition Examination Survey. 
out. First, the Amish tend to be far more physically active than their non-Amish counterparts, as we ${ }^{14}$ and others ${ }^{15} 16$ have previously documented. The protective effects of physical activity on cardiometabolic health are well documented, including in the Amish, ${ }^{17}$ and the more active Amish lifestyle may contribute to less diabetes, hypertension, and high cholesterol in this population. Second, the structure of Amish culture is very different from the nonAmish, and some aspects of this culture may confer additional benefits to cardiometabolic health. For example, Amish culture is very socially cohesive and at its core lies a strong ethos of community and family support. One can imagine that such a culture could be beneficial for dealing with stress. It is also possible that components of the Amish diet confer protection against these common cardiovascular risk factors. In sum, the relation of Amish culture to health is undoubtedly complex, and this is a topic in need of future study.

An intriguing observation from our study is that Amish have substantially lower fasting glucose levels compared with NHANES despite slightly higher levels of HbAlc. We have no clear explanation for this, and it is unlikely to be due to assay issues because glucose and HbAlc were measured in a central standardized lab (Quest). Possibly, glycemic excursions are not well captured in the Amish by a single fasting glucose. Amish do have slightly longer fasting times compared with NHANES, although this alone accounts for very little of the discrepancy. Amish, who tend to wake up early, may also be more physically active during the fasting period compared with nonAmish potentially contributing further to lower fasting glucose levels. It is also possible that non-glycemic factors (eg, red cell turnover and overall physical activity levels) may be at play that contribute to low fasting glucose levels in the Amish or to a mismatch of glucose and HbAlc levels.

One limitation of our study is that it is based on crosssectional data. The possibility must therefore be considered that the incidence of one or more of these disorders could be similar between Amish and NHANES but Amish with these conditions might experience reduced survival, thus resulting in a lower prevalence. In fact, we have previously documented that Amish in general have less access to medical care. ${ }^{18}$ Although we are aware of no data specifically addressing case fatality from these conditions in the Amish, we regard this possibility as unlikely since overall mortality among Amish adults is very similar to that observed in the Framingham Heart Study Cohort, although this prior analysis was restricted to individuals born between 1890 and $1921 .^{18}$ Our survey is based on a sample of the Amish community, and the frequencies of these disorders in this sample may not represent those in the overall community.

In summary, we have demonstrated that Amish have a substantially lower prevalence of diabetes and hypertension compared with NHANES and a moderately lower prevalence of high cholesterol. The reasons for these prevalence differences are not known although likely relate to distinctive features of the Amish lifestyle and community that may be protective for cardiometabolic health, such as the relative high levels of physical activity and the cohesive and supportive structure of the Amish community.

Acknowledgements The authors would like to acknowledge the substantial contributions of other staff members at the Amish Research Clinic, including Elizabeth Zehr, Tracy Broderick, Grace Redcay, Fred Young, Regina Guaraldi, Mary Morrissey, Theresa Roomet, and Mary McLane, as well as the many Amish liaisons who have contributed to these studies (Sarah Fisher, Sadie Fisher, Katie Stoltzfus, Mary Esh, Anna Esh, Naomi Esh, Susie Fisher, Hanna King, Sylvia King, Verna Petersheim, Barbie A Stoltzfus, Barbie B Stoltzfus, Fannie Stoltzfus, Mary Stoltzfus, Susie Stoltzfus, Lydia Zook, and Esther Smucker).

Contributors Conceived and drafted the paper: SH and BDM; analyzed and interpreted data and drafted the manuscript: $\mathrm{SH}$ and KAR; data collection: MeD, DT, YR, PD, MaD, SN, SS and NW; commented on the drafts of the paper: KAR, EAS, PFM, ARS and TP; all authors have approved the final version for submission.

Funding This work was supported in part by National Institutes of Health grant P30 DK072488, the Regeneron Genetics Center, and the University of Maryland School of Medicine Program for Personalized and Genomic Medicine.

Competing interests ARS is an employee of Regeneron Pharmaceuticals, Inc and receives compensation.

Patient consent for publication Not required.

Ethics approval This study was approved by the Institutional Review Board at the University of Maryland, Baltimore (University of Maryland, Baltimore IRB HP-00043451).

Provenance and peer review Not commissioned; externally peer reviewed.

Data availability statement Data are available on reasonable request. Data may be obtained from a third party and are not publicly available. Some deidentified Amish data are available on dbGaP (dbGaP Study Accession: phs000956.v3.p1) Further inquiries may be directed to the communicating author. National Health and Nutrition Examination Survey (NHANES) data are available through NHANES.

Open access This is an open access article distributed in accordance with the Creative Commons Attribution Non Commercial (CC BY-NC 4.0) license, which permits others to distribute, remix, adapt, build upon this work non-commercially, and license their derivative works on different terms, provided the original work is properly cited, appropriate credit is given, any changes made indicated, and the use is non-commercial. See: http://creativecommons.org/licenses/by-nc/4.0/.

ORCID iD

Braxton D Mitchell http://orcid.org/0000-0003-4920-4744

\section{REFERENCES}

1 Benjamin EJ, Virani SS, Callaway CW, et al. Heart disease and stroke Statistics-2018 update: a report from the American heart association. Circulation 2018;137:e67-492.

2 Danaei G, Ding EL, Mozaffarian D, et al. The preventable causes of death in the United States: comparative risk assessment of dietary, lifestyle, and metabolic risk factors. PLoS Med 2009;6:e1000058.

3 Egan BM, Zhao Y, Axon RN. Us trends in prevalence, awareness, treatment, and control of hypertension, 1988-2008. JAMA 2010;303:2043-50.

4 Egan BM, Li J, Hutchison FN, et al. Hypertension in the United States, 1999 to 2012: progress toward healthy people 2020 goals. Circulation 2014;130:1692-9.

5 Menke A, Casagrande S, Geiss L, et al. Prevalence of and trends in diabetes among adults in the United States, 1988-2012. JAMA 2015;314:1021-9.

6 Carroll MD, Kit BK, Lacher DA, et al. Trends in lipids and lipoproteins in US adults, 1988-2010. JAMA 2012;308:1545-54.

7 Carroll MD, Fryar CD, Kit BK. Total and high-density lipoprotein cholesterol in adults: United States, 2011-2014. NCHS Data Brief 2015;226:1-8.

$8 \mathrm{Gu}$ Q, Paulose-Ram R, Burt VL, et al. Prescription cholesterollowering medication use in adults aged 40 and over: United States, 2003-2012. NCHS Data Brief 2014:1-8.

9 Adabag AS, Luepker RV, Roger VL, et al. Sudden cardiac death: epidemiology and risk factors. Nat Rev Cardiol 2010;7:216-25. 
10 Pollin TI, McBride DJ, Agarwala R, et al. Investigations of the $Y$ chromosome, male founder structure and YSTR mutation rates in the old order Amish. Hum Hered 2008;65:91-104.

11 Shen H, Damcott CM, Rampersaud E, et al. Familial defective apolipoprotein B-100 and increased low-density lipoprotein cholesterol and coronary artery calcification in the old order Amish. Arch Intern Med 2010;170:1850-5.

12 Hsueh WC, Mitchell BD, Aburomia R, et al. Diabetes in the old order Amish: characterization and heritability analysis of the Amish family diabetes study. Diabetes Care 2000;23:595-601.

13 Montasser ME, O'Hare EA, Wang X, et al. An APOO pseudogene on chromosome $5 \mathrm{q}$ is associated with LDL-C levels. Circulation 2018;138:1343-55.
14 Hairston KG, Ducharme JL, Treuth MS, et al. Comparison of BMI and physical activity between old order Amish children and non-Amish children. Diabetes Care 2013;36:873-8.

15 Bassett DR, Schneider PL, Huntington GE. Physical activity in an old order Amish community. Med Sci Sports Exerc 2004;36:79-85.

16 Bassett DR, Tremblay MS, Esliger DW, et al. Physical activity and body mass index of children in an old order Amish community. Med Sci Sports Exerc 2007;39:410-5.

17 Mitchell BD, Kalra G, Ryan KA, et al. Increased usual physical activity is associated with a blunting of the triglyceride response to a high-fat meal. J Clin Lipidol 2019;13:109-14.

18 Mitchell BD, Lee W-J, Tolea MI, et al. Living the good life? mortality and hospital utilization patterns in the old order Amish. PLoS One 2012;7:e51560. 